\title{
APPLICATION OF INDUSTRIAL METHODS IN ENGINEERING EDUCATION
}

\author{
Simon KIND ${ }^{1}$, Anton DYBOV ${ }^{1}$, Christian BUCHHOLZ ${ }^{1}$ and Rainer STARK ${ }^{1,2}$ \\ ${ }^{1}$ Department of Industrial Information Technology, Technische Universität Berlin \\ ${ }^{2}$ Fraunhofer Institute for Production Systems and Design Technology
}

\begin{abstract}
Modern trends and challenges like an increased level of product complexity and reduced time for development require new, improved skills for future employees. Potential industrial methods based on early project planning, interdisciplinary product solutions and a systematic preparation for production are researched and presented within this paper. Future employees need to understand the processes and methods of product implementation and production. Especially the last stages of product development require additional attention, since these are the most challenging phases regarding integration and implementation starting from initial prototyping up to a functional product.

Industrial feedback proves, that these skills are not taught in an appropriate extend by todays academic education, concluding that todays' graduates are not well prepared for tomorrow's job challenges. Following the gaps in today's education a student project lecture was developed, that teaches and applies industry-related development methods addressing advanced master students.

Focus of the related student project includes a constant review of project management practices in industrial design reviews, as well as the gathering and definition of requirements. In addition to this, development methods for functional prototypes are taught and applied. Especially the actual creation of prototypes is addressing the product integration and testing phase. To present the above-mentioned methods and an innovative testing environment, two successfully applied use cases are described within this paper. These are covering the entire development process starting from early requirements gathering, accompanied by model-based system engineering.
\end{abstract}

Keywords: Systems engineering, early product and process verification, interactive design reviews, prototyping methods

\section{INTRODUCTION}

An increased level of product complexity, more individualised products, reduced time for development until delivery and an interconnected and globalised way of cooperation are actual trends in modern product development processes [1].

Systems engineering processes and methods are used to address this complexity by offering an iterative process of top-down synthesis and the operation of a real-world system that satisfies the full range of requirements for the system [2]. Thereby systems engineering integrates all the disciplines and specialty groups into a team effort forming a structured development process that proceeds from concept via production to operation $[3,4]$. Employees in systems engineering based development processes need a dramatically expanded knowledge in new working methods and tool usage skills. Especially the increased usage of digital development tools is based on the employee's expertise in designing useful models and prototypes and to evaluate their requirements with appropriate tests. Furthermore, manual work in production is replaced by automated equipment: This equipment has to be operated by production engineers that are able to integrate digital models from systems engineering development processes. Therefore, key elements of competent employees in engineering are the understanding of an entire systems engineering development process in a holistic way. Industrial feedback proves, that these skills are not taught in an appropriate extend by today's academic education, concluding that today's graduates are not well prepared for tomorrow's job challenges [5]. 


\section{SYSTEMS ENGINEERING IN PRODUCT DEVELOPMENT AND PRODUCTION PLANNING}

Mechatronic system development processes can be described with the so called "V-Model", first introduced in 1979 for software development projects [6]. The V-Model describes a documentation and product model that represents which processes, system elements and sub-products are involved in integrated product development and how they relate to each other [7]. Today, various representations of the V-Model are used in industrial practice, in most cases specifically customised to the requirements of the developed product or respective company [8]. Besides these company specific differences, all VModel oriented development processes are based on similar characteristics:

As shown in Figure 1 [9], the entire product development process is covered: Starting from product planning the process model describes an integrated systems design at the V's left branch for requirement specification and the definition of function-oriented system models. These "Mechatronic System Specifications" are partitioned into models that are usable for the domain specific development of mechanics, Electrics/Electronics (E/E) and software. The prototypes created in domain-specific development are transferred into integrated prototypes on the V's right branch. These integrated prototypes are tested with different test methods to confirm the property development according to requirements: Starting from completely virtual prototypes via hybrid prototypes - tested in mixed test environments that consist of physical and virtual elements - up to product-oriented prototypes, that are close to the final product. These can consist of well-developed physical mechanics and E/E-prototypes and software code. The development process finishes with the finalisation of the product itself, developed according to the mechatronic system specifications.

Simultaneously with the start of domain specific development, the process of service development, as well as process and resource planning starts. Especially the execution of the process and resource planning is crucial for following production processes, as processes, methods and tools are defined in an early collaboration with the development domains.

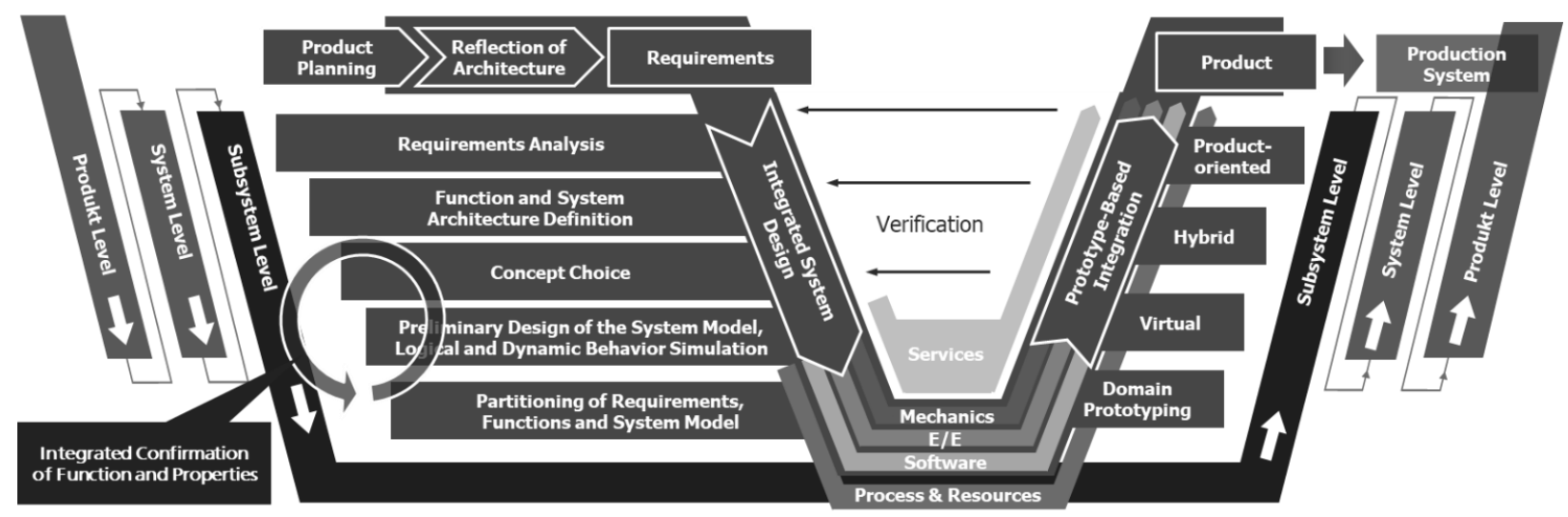

Figure 1. MBSE Process model of model-based design and prototype-based integration [9]

Although todays production facilities consist of mechatronic systems as well, systems engineering based development is not commonly applied in today's production planning [10]. Rather than using iterative development processes, production planning is mostly based on linear processes, as described by VDI 5200 [11]. Nevertheless, new approaches using iterative, V-Model based processes are researched to be the implemented in future process planning as well $[12,13]$.

Today's development processes are supported by methods and software tools, that enable an efficient collaborative operation. These tools create multiple, computer operated models, which qualify to support model based systems engineering approaches (MBSE). Table 1 shows common industrial MBSE methods and tools, both for product development and production planning.

To ensure, that the development process is fulfilling the defined criteria to satisfy client's requirements and completing product development in time and budget, project management is a key factor in each interdisciplinary project [14]. In addition to the MBSE methods and tools mentioned above, project management skills were considered and researched for transfer to engineering education as well. 
Table 1. Common industrial method and tools in product development

\begin{tabular}{|l|l|l|}
\hline Process Step & Method & Development Tool \\
\hline \multirow{3}{*}{ System Design } & Requirements Definition and Management & Doors \\
\cline { 2 - 3 } & System Modelling & $\begin{array}{l}\text { UML/SysML Modeler, } \\
\text { e.g. Enterprise Architect }\end{array}$ \\
\hline Domain specific design & Mechanical Design & CAD Tool, e.g. CATIA, NX \\
\cline { 2 - 3 } & Electrics/Electronics (E/E) & $\begin{array}{l}\text { 3DExperience, EPLAN, } \\
\text { Eagle }\end{array}$ \\
\cline { 2 - 3 } & Software & Git, SVN tools \\
\hline \multirow{2}{*}{$\begin{array}{l}\text { System Integration and } \\
\text { Validation } \\
\text { \&Verification }\end{array}$} & System Simulation & $\begin{array}{l}\text { CASE-Tool, e.g. Dymola, } \\
\text { MATLAB }\end{array}$ \\
\cline { 2 - 3 } & Process Simulation & $\begin{array}{l}\text { Process Sim Tool, } \\
\text { e.g. DELMIA, Tecnomatix }\end{array}$ \\
\cline { 2 - 3 } & Commissioning, material flow & Plant Simulation \\
\hline
\end{tabular}

\section{INDUSTRIAL METHODS IN SYSTEMS ENGINEERING EDUCATION}

Based on an analysis of todays and future processes, methods and tools in Product development and production planning, the following elements were taken as a conclusion for academic education:

1. The students need to be prepared, to understand and work in multidisciplinary, industrial Systems Engineering development processes

2. State of the art Model Based Systems Engineering methods and tools need to be taught and applied to exercise holistic approaches as well as software tool skills and competences

3. Project management methods, modelling and simulation tools need to be included in lectures and also in project-based exercises

4. Prototype creation, testing and verification in accordance with an accurate test plan should always be part of the related student project

Following [1,15], experiential learning, as a problem-based learning approach is a promising way of teaching, that confronts students with real-life problems and provides them with the opportunity to apply their concept. It is an appropriate didactic format to implement systems engineering methods in academic education.

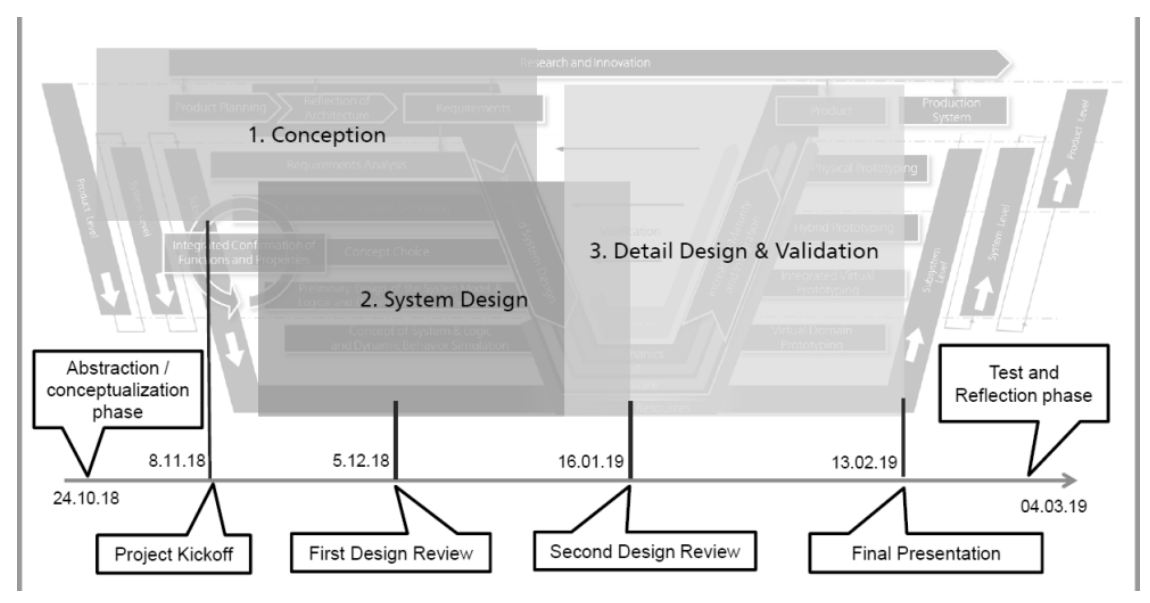

Figure 2. MBSE based academic project process

The following model-based system engineering (MBSE) approaches are directly reflected in educational lectures and exercises (following figure 2).

Starting with a correct and high-quality planning of project activities, the correct allocation of resources and the distribution of roles between participants needs to be ensured. In addition, it is necessary to pay attention to the analysis of the list of requirements and a preparation of precise technical specifications, because product quality strongly depends on these.

As in industry and in educational projects it is necessary to pay attention to the development of product models and their joint integration into a prototype at an early stage. This allows to finish the project 
faster and reduce the number of errors at a late stage of product development. In addition, the joint work of the participants needs to be traced at each stage of the project.

One of the key elements of industrial methods in education process are design reviews and a final presentation. Each review and the final presentation relate to certain strict rules. Student teams take the role of emerging companies, that compete with each other in the quality of a project. The teaching staff acts as a project customer, that evaluates the work of each team and decides, to whom they will invest resources.

During design reviews the student teams present current results of the project and talk about the problems that have been addressed. They have a limited timeframe for project presentation and to answer to questions. At the end of the design review the teams receive feedback and recommendations for the next working steps. An example of a design review is shown in figure 3. At the end of each semester, student teams must defend their project during a final presentation, which consists of two parts presentation and demonstration.

The presentation starts with an elevator pitch and continues with the project presentation. The teams are supposed to focus on the final system design and systems validation methods. During presentation the following questions need to be answered:

How does the system work? How is the system validated? Does the system meet all requirements?

The demonstration part consists of the tests for the created prototypes in real-time environment. Two examples of prototypes are shown in figure 4. With the help of a group of tests, the team describes the most important function of the product. For this they can use Functional Digital Mock Up (FDMU), Model-in-the-Loop (MiL) or co-simulation methods. Based on the results of the final presentation the companies' customer reflects which project was providing the most added values.

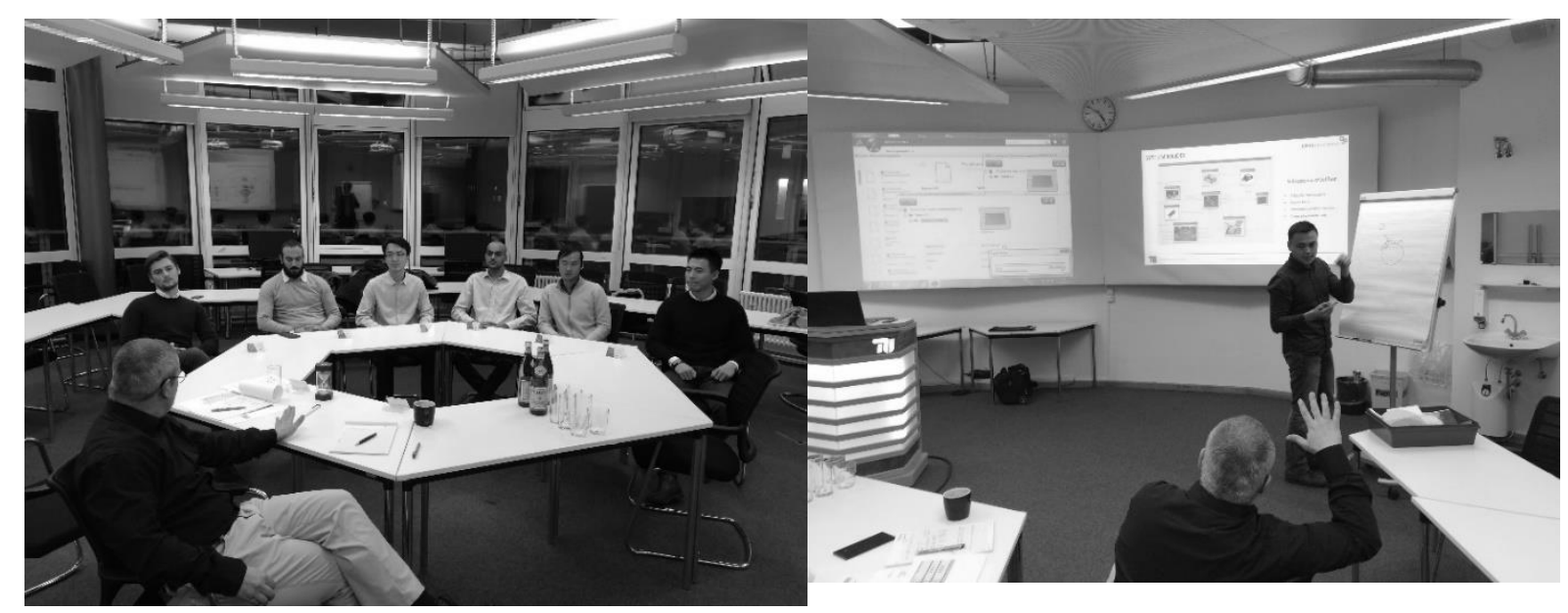

Figure 3. Design review in education classes

\section{APPLICATION OF NEW APPROACH IN ENGINEERING EDUCATION}

In this chapter two successfully applied use cases for using MBSE and prototyping approaches in engineering education are presented. Both use cases are related to automotive product development processes. One use case is focusing on the development of an advanced driving assistant system (ADAS) to prevent car-bike accidents, the second one is based on planning and validation of the production process for cockpit assembly tasks.

Following the V-Model (figure 2) the interdisciplinary student teams, that applied to the corresponding lectures, were asked to specify requirements for their semester tasks, define and continuously take care of project planning and provide an initial design concept. Based on a structured system architecture, the first project phase was reviewed within a design review to cross-check the preparation for the following detailed design phase with the customer.

Modelling, simulating and testing initial, domain-specific prototypes within the $2^{\text {nd }}$ project phase resulted in significant simulation results for the planned product (ADAS) and cockpit production line. These needed again to be presented, consulted and approved with the customer in a second design review. Based on these initial, domain-specific prototypes the student teams needed to provide a consistent test and verification plan, to be able to move on to the last project phase, that is focusing on integration, creating hybrid prototypes and verifying the defined requirements. 
This last stage of the project is covering the right branch of the V-Model and includes the development of a functional prototype and the integration of all models into a system level prototype. Starting off with completely virtual prototypes, that were created within initial design phase, these were more and more enhanced by physical elements, to be able to also test the corresponding human-machine interaction. The integration phase was successfully finished by ending up with hybrid and also physical parts, that resemble the actual behaviour of the final product and production system. The robustness of the created prototypes was checked along the provided test and verification plan. To conclude and summarise the entire development process the student teams needed to present the results to the customer within the final presentation.

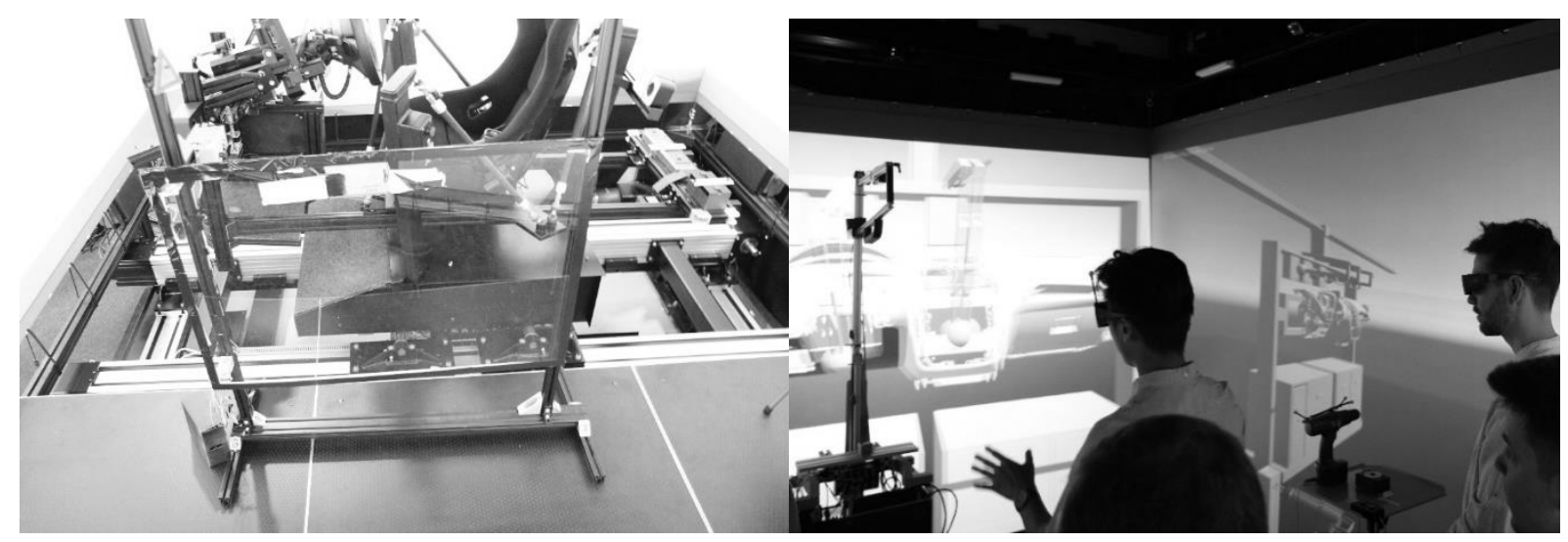

Figure 4. Hybrid Prototyping Device for Testing and Validation in Product Development (Left) and in Production Planning (Right)

The results of the student work regarding the application of systems engineering methods is a hybridprototyping device of a car door with an active and passive warning system for the driver, that is detecting an approaching cyclist (figure 4 , left). The final prototype consists of integrated mechatronic elements on a system level that represent the physical product behaviour. This solution is implemented and based on Arduino microcontrollers with connected elements for sound, light and tactile alerts.

The second use case provided a holistic view for an entire cockpit production system. The final prototype (figure 4, right) is based on an accurate layout planning and simulation of the material flow of one single production line. After enhancement with physical elements of one manufacturing task, it was also possible, to verify the simulation results of a specific manual assembly station. Major verification criteria were assembly verification, reachability tests, ergonomics analysis and the actual manufacturing time. The entire development process for both use cases were accompanied by applying project management.

\section{SUMMARY AND CONCLUSION}

While working on the project, student teams faced a number of challenges and issues. In the beginning of the student project, the teams found it very difficult to find the correct rhythm of work and adapt themselves to complete tasks before deadlines. Initial uncertainty regarding application of design reviews, feedback regarding systems engineering roles including a holistic product and production process development were observed. As a second observation, the student teams were surprised and overwhelmed by the format and the interactive structure during the first design review initially facing their potential customers. It was difficult for the teams to imagine the role of future engineers in a company to present their project results in a brief and precise way, even often missing the opportunity to present their full spectrum of results.

In comparison to the first design review, the domain specific results presented at the second design review were consistent and high quality based. It is assumed, that this results from usage of domain models as CAD-models or software code, that are well known from former academic experience. Thus, most results of the domain development phase were successfully presented.

Challenges during the final presentation were observed in performing life tests to prove the integrated prototype to meet the system specifications: In most of the cases, the commissioning and operation of the hybrid prototype showed to be prone to error and offered a collection of new, unknown failures. Nevertheless, students reported this task to be useful - not only to reveal weak spots of design product 
and production system in real-time environment - but also doing this, while being observed by their potential customer.

In review of the mentioned points, the following conclusion can be identified: Students need to be educated and trained in a learning environment close to industrial standards. They should have the opportunity to distribute roles among themselves in a team to learn time-management within the project and to plan future steps and results.

For future courses, the provision of additional time to mutual understanding of engineers and students, especially in the early stages of product development is useful. For this, it is necessary to conduct preliminary training of participants, both in educational institutions and at enterprises. In addition, it's important to highlight the positive aspects of system engineering methods that help to structure work tasks and specify requirement lists. In addition to this, the actual value of a precise test and verification plan turns out very clear, especially pointing out the distinguished functionalities of the product and a successful development of hybrid prototypes.

\section{REFERENCES}

[1] Buchholz et. al. Cross disciplinary application of system Engineering approaches in multidisciplinary education projects, E\&PDE, Aalburg 2016

[2] Eisner H. Essentials of Project and Systems Engineering Management. 2002, p5

[3] Walden D.D. et. al., Systems engineering handbook: a guide for system life cycle processes and activities, by International Council on Systems Engineering (INCOSE), 2015, p11

[4] Sünnetcioglu A. et al. Durchgängiger Traceability-Process im Systems Engineering. In: Tag des Systems Engineering, 2014, DOI: 10.3139/9783446443761.014.

[5] Butting A. et al., Teaching model-based systems engineering for industry 4.0: student challenges and expectations. In: 21st ACM/IEEE International Conference, pp. 74-81, 2018, DOI: $10.1145 / 3270112.3270122$.

[6] Boehm B.W. Guidelines for Verifying and Validating Software Requirements and Design Specifications, 1979, Holland, p71ff

[7] Eigner R. et al. Modellbasierte virtuelle Produktentwicklung, 2014, Berlin, 35-36

[8] Stark R. et. al. Virtuelle Produktentstehung in der Automobilindustrie, Informatik Spektrum $1 / 2011, \mathrm{p} 20$

[9] Buchholz C., Tiemann M. and Stark R. Durchgängiges Prototyping mechatronischer Systeme im MBSE Entwicklungsprozess, DFX Symposium, Tutzing, D., 2018, p126

[10] Neumeyer S., Kind S. and Stark R. Virtual prototyping and validation of CPPS within a new software framework, IN: Proceedings of the $7^{\text {th }}$ Cirp IC-SCCE, Athens, 2016

[11] VDI 5200, factory planning, planning procedures, (2011), ICS 03.100.99

[12] Stark R., Kind S. and Neumeyer S. Innovations in digital modelling for next generation manufacturing system design, In: CIRP Annals Manufacturing Technology, 2017, Lugano

[13] Stark R., Müller P. and Grosser H. ViB-SHP - Virtuelle Inbetriebnahme für Industrie 4.0 zukunftssicher beherrschen - Modulare Gestaltung und immersive, digitale Absicherung von mechatronischen Produktionsanlagen, Fraunhofer Verlag, 2018, ISBN: 978-3-8396-1416-7

[14] White D. and Fortune J. Current practice in project management - an empirical study, International Journal of Project Management, 1/2012

[15] Brewer P. et al., Teaching and Learning in Cross-Disciplinary Virtual Teams. IEEE Transactions on professional communication, Vol. 58, No. 2, 2015, pp. 208-229 